\begin{abstract}
Iranica
Abstracta Iranica Revue bibliographique pour le domaine irano-aryen

Volume 42-43 | 2021

Comptes rendus des publications de 2019-2020
\end{abstract}

\title{
Philippe Gignoux. Un livre de pharmacopée en syriaque
}

Florence Jullien

\section{(2) OpenEdition}

Journals

Édition électronique

URL : https://journals.openedition.org/abstractairanica/53109

DOI : 10.4000/abstractairanica.53109

ISSN : 1961-960X

Éditeur :

CNRS (UMR 7528 Mondes iraniens et indiens), Éditions de l'IFRI

Référence électronique

Florence Jullien, «Philippe Gignoux. Un livre de pharmacopée en syriaque », Abstracta Iranica [En ligne], Volume 42-43 | 2021, document 9, mis en ligne le 30 décembre 2021, consulté le 12 décembre 2022. URL : http://journals.openedition.org/abstractairanica/53109; DOI : https://doi.org/10.4000/ abstractairanica.53109

Ce document a été généré automatiquement le 12 décembre 2022.

Tous droits réservés 


\title{
Philippe Gignoux. Un livre de pharmacopée en syriaque
}

\author{
Florence Jullien
}

\section{RÉFÉRENCE}

Philippe Gignoux. Un livre de pharmacopée en syriaque. Leuven: Peeters, 2019, 121p., ISBN : 978-9042937413, (CSCO 670, Syr. 258).

1 L'A. est un familier de la pharmacologie en milieu syriaque comme en témoigne nombre de ses publications, consacrées notamment aux relations interlinguistiques entre les termes syriaques, grecs et pehlevis dans ce domaine peu exploré. On sait combien les textes scientifiques, et spécialement de pharmacopée, ont influencé le milieu mazdéen comme arabe, à la faveur des transmissions des héritages grecs en particulier. Comme le signale l'A., «ce petit livre pourrait être une introduction à la pharmacopée orientale ». Il offre ici l'édition critique (avec texte syriaque en vis-à-vis) d'une œuvre syriaque anonyme sur les médications ; ce travail est effectué à partir d'un manuscrit inédit (BNF syr. 423) apparenté au ms. Mingana syr. 594. Reprenant en partie Galien, le traité ne semble pourtant pas être la traduction d'un livre grec. Il comporte nombre de mots spécialisés comprenant les noms de plantes médicinales et ceux de minéraux ou animaliers qui entraient dans la composition des recettes pharmacologiques, dont l'A. détermine avec soin l'origine linguistique et qui sont souvent des gloses, dérivant directement du grec pour la plupart, mais aussi du moyenperse, de l'arabe, du persan et de l'arabo-persan. Ce travail minutieux montre une fois de plus l'importance de la culture syriaque comme passerelle vers le milieu arabe, et lève le voile sur l'intérêt de cette vaste et fascinante littérature botanique. 


\section{AUTEURS}

FLORENCE JULLIEN

CNRS, CeRMI, Paris 